\title{
Infectious Diseases in China
}

\author{
Zeng $\mathrm{Yi}^{1}, \mathrm{Xu} \mathrm{Hua}^{1}$, and Zhang Jiaxi ${ }^{2}$ \\ ${ }^{1}$ Chinese Foundation for Prevention of STD and AIDS, Beijing, China \\ ${ }^{2}$ China Preventive Medicine Association, Beijing, China
}

\section{HISTORY OF INFECTIOUS DISEASES}

Before 1949, many epidemic diseases occurred in China due to corruption in the government, foreign invasions, and poor technologies. According to Chinese history, up to 305 years prior to the founding of the People's Republic of China (P.R.China), a plague epidemic affecting a total of 2.6 million people caused 2.4 million deaths. Smallpox epidemics occurred every year. Between 1933 and 1944 , about 380,000 people contracted smallpox. In 1820 , cholera was introduced into China; since then there have been about a hundred of serious cholera epidemics in China. Schistosomiasis once reached a two million square kilometer epidemic area, with 11 million people contracting the disease. There were hundreds of thousands of people who died or became disabled from measles, malaria, diphtheria, pertussis, meningococcal meningitis, and polio. Due to the lack of a basic infectious disease reporting system, statistics were very difficult to accurately obtain and monitor. Epidemics of sexually transmitted infections (STI) were rampant in both urban and rural areas; these were regarded as a social issue. In China's five thousand years of history, no governments have had the capability to control infectious epidemics and to establish a national epidemic preventive system.

In the early days of the founding of P.R.China, the Chinese government faced tough challenges. For example, in 1950, there were about 3400 human plague cases with 1200 deaths; 43,000 and 61,000 smallpox cases were reported respectively in 1951 and in 1952. In 1952, there were 1.04 million measles cases with 41,000 deaths, and 2.93 million malaria cases with 39,000 deaths reported (Ministry of Public Health, 1990; 2002). Pertussis, kala-azar, diphtheria, and relapsing fever were rampant. In 1951, a relapsing fever epidemic occurred, affecting 100,000 Chinese with relapsing fever and causing more than 10,000 deaths. STI epidemics were very severe; the incidence rate of syphilis in large cities was 3.8\%-4.5\%, and in some minority areas the rate reached from $21.7 \%$ to $48 \%$. Among the female sex workers (FSW) in Beijing, Shanghai, Wuhan, and Guishui, the incidence rate of STI was between $89.3 \%$ and $100 \%$. To confront these challenges, the Chinese government carried 
out a "Put prevention first" principle, established an anti-epidemic system nationwide, and concentrated its efforts to prevent and control severe and life threatening infectious diseases. With a focus on infectious disease prevention and treatment, the Chinese government developed a national health campaign, and enforced occupational health, food hygiene, school hygiene, and radiation protection regulations. Through these strategies, the sanitation situation in urban and rural areas has greatly changed, and citizens' health status has been greatly improved.

By the end of the 1950s, China had basically eliminated smallpox, plague, kalaazar, typhus, relapsing fever, and STI. By the end of 2002, the morbidity rate of notifiable infectious diseases had decreased from $20,000 / 10^{5}$ at the beginning of the founding of P.R.China to $180 / 10^{5}$ in 2002 . The total incidence number for measles, pertussis, and diphtheria has decreased from 11.83 million to 56,252 (Ministry of Public Health, 1990; 2002). There have now been four consecutive years without a reported case of wild virus strain polio. The morbidity rates for schistosomiasis, filariasis, malaria, and leprosy have also decreased significantly. However, infectious diseases are key health issues within specific regions of China. In recent years, some infectious diseases have reemerged, such as tuberculosis, malaria, and STI. Other new diseases like AIDS and SARS have emerged to threaten the lives and health of the Chinese, as well as China's economic development.

\section{HEALTH CARE INSTITUTIONS}

Health care institutions in China originated in 1873 when the first health Quarantine institutions were constructed. In 1919, the first anti-epidemic department was started in the North of China.

In 1949, based on the experience and practices of the former USSR, a health antiepidemic station was set up in the former Zhong Chang Railway Administration in the
Northeast of China. After the founding of the P.R. China, according to the principle of the Chinese government "To put prevention first," health anti-epidemic stations were set up in several provinces and cities of China. By the end of 1952, there were 147 such stations, 188 special preventive and treatment services, with 20,504 health anti-epidemic workers, including 19,750 health technical personnel. By the end of 1956, the health anti-epidemic stations covered most of China, except the areas of minority nationalities and remote areas. The health anti-epidemic stations were also set up within the railway system, and in large factories, mines, and enterprises. In addition, preventive and care sections were set up in the county hospitals and the health anti-epidemic groups were set up in the township health institutions. By 1965, there were 2499 health anti-epidemic stations at all levels and 822 preventive and treatment institutions, with 63,879 health technical personnel throughout China. This represents a 16-fold increase compared with 1952 (Chinese Association of Preventive Medicine, 2003).

During the Cultural Revolution, the health anti-epidemic system and its services were seriously impacted. After the Cultural Revolution, the health anti-epidemic system and its services were resumed and further developed.

In 1983, in order to increase the capabilities of the health system, the National Preventive Medical Center was set up by the ministry of Health (it was changed to the Chinese Academy of Preventive Medicine in 1985, and changed to National Centers for Disease Prevention and Control in 2002). In 2002, there were 3580 Centers for Disease Prevention and Control, including 31 Centers at the provincial level, 383 at the prefecture level, 2519 at the county level, and 637 in other fields. There were a total of 204,444 personnel, including 156,838 health technical workers. China, in 2002 , had as well 1839 special prevention and treatment institutions, and 571 health supervision services (Chinese Association of Preventive Medicine, 2003). 


\section{HIV/AIDS PREVENTION AND CONTROL}

\section{Epidemic Situation}

In 1982, Clotting Factor VIII with HIV-1 was sent from the USA to China; during 19831985, four Hemophilia patients were infected with HIV-1 through the injection of this Factor VIII from the USA. In 1985 the first AIDS patient came to China from the USA and died in China.

The cumulative reported number of people living with HIV/AIDS (PLWHA) had reached 40,560 by the end of 2002 , with a total of 2639 AIDS cases and 1216 AIDS-related deaths in the 31 provinces, autonomous regions, and municipal cities in China except Taiwan, HongKong and Macao (see Figure 1). In 2002, 9824 new HIV infections were reported; reflecting a $19.5 \%$ increase over the same period in 2001. The number of infections has increased in 26 provinces, autonomous regions, and municipal cities in China. Among these, Hainan, Guizhou, Chongqing, Hubei, Hunan, and Anhui provinces reported that the number of PLWHA had an increase compared to the figure reported in the same period of 2001. In 2002, 1045 AIDS cases were reported, with 363 AIDS-related deaths, another increase from the previous year. Among reported cases, 4928 were infected through intravenous drug use, accounting for $50.2 \%$ of infections; infection through blood and blood products accounted for $10 \%$ of infections; heterosexual contact for $11 \%$; maternalto-child transmission (MTCT) for $0.4 \%$; and $28.3 \%$ of infections occurred through unknown transmission modes. Statistics also show that $78.4 \%$ of reported infections are among young people aged 20 to 39 (China HIV/AIDS Information Network, 2002).

Between 1985 and 2002, most HIV/AIDS cases were reported in the Yunnan province, followed by Xinjiang, Guangxi, Guangdong, Sichuan, and Henan provinces (see Figure 2). HIV/AIDS cases have been mainly distributed in the rural areas.

The proportion of male and female cases is 4:1 (see Figure 3).

HIV infection among different age groups is: $1 \%$ for age $<15 ; 5.9 \%$ for ages $15-20 ; 51.1 \%$ for ages $20-29 ; 28.9 \%$ for ages $30-39 ; 10 \%$ for age $>40 ; 3 \%$ unknown (see Figure 4).

The major modes of transmission for HIV/AIDS in China since 1985 have been: intravenous drug use (IDU), accounting for $63.7 \%$ of infections; infection through the whole blood supply accounted for $9.3 \%$ and blood products accounted for $1.6 \%$; heterosexual contact for $8.1 \%$; MTCT for $0.2 \%$, and unknown for $17.1 \%$ (see Figure 5).

This year, according to a joint HIV/AIDS epidemiological survey conducted by China, WHO, and UNAIDS, China has an estimated 840,000 persons living with HIV/AIDS, including 80,000 AIDS cases. Experts estimate

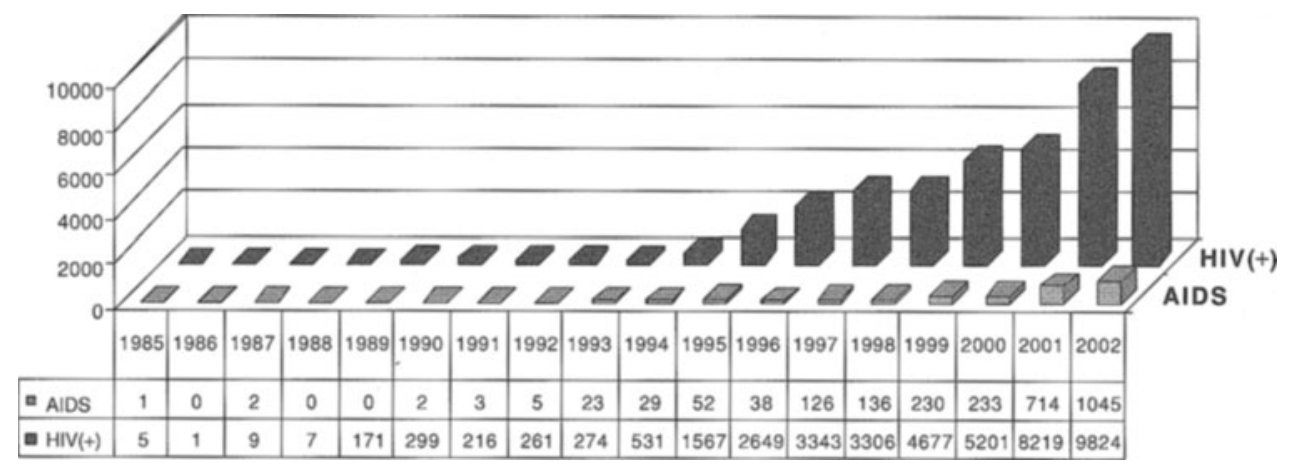

FIGURE 1. Annual Reported Number of HIV/AIDS Cases in China (1985-2002) 


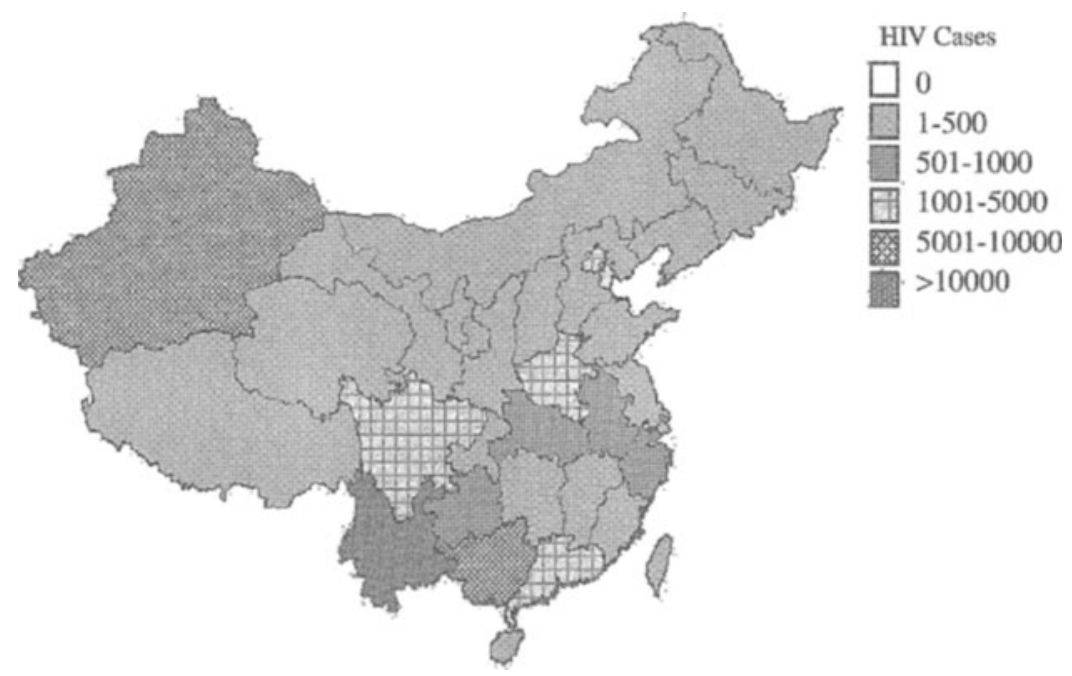

FIGURE 2. Geographic Distribution of HIV/AIDS in China (1985-2002)

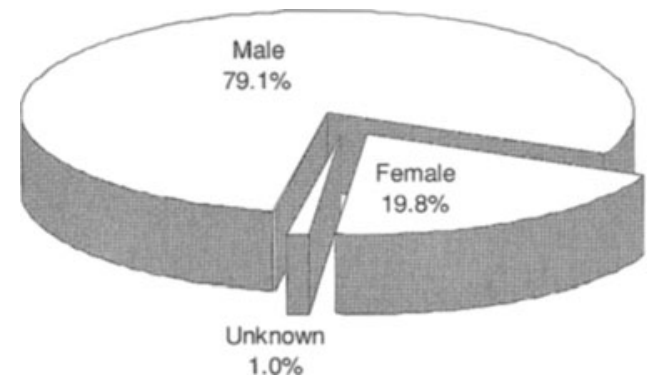

FIGURE 3. Gender Distribution of HIV Infection in China (1985-2002)

there will be 10 million HIV/AIDS cases without effective control (see Figure 6).

\section{Three Phases of the HIV Epidemic in China}

\section{The First Phase}

The first phase, which began in 1985 and end in 1988 was marked by a small number of imported cases. The majority of infected persons during this time were foreigners or overseas Chinese, and the cases appeared only sporadically in coastal cities. Four hemophiliac patients infected with HIV through imported factor VIII were reported from Zhejiang.

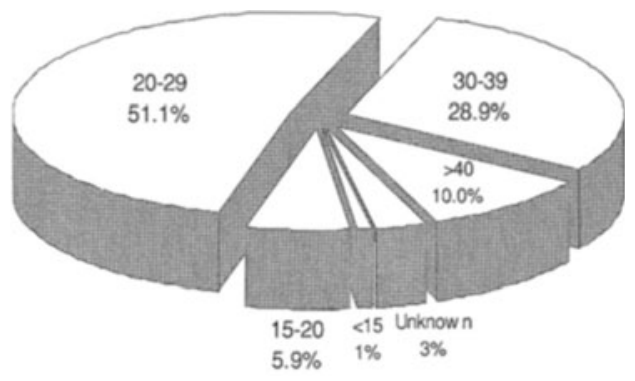

FIGURE 4. Age Distribution of HIV Infection in China (1985-2002)

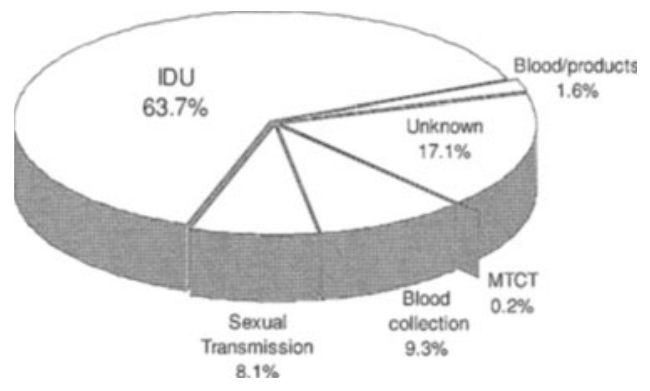

FIGURE 5. Reported HIV Infections in China by Transmission Route (1985-2002)

\section{The Second Phase}

The second phase, from 1989 to 1994 , might be termed a limited epidemic. It began 


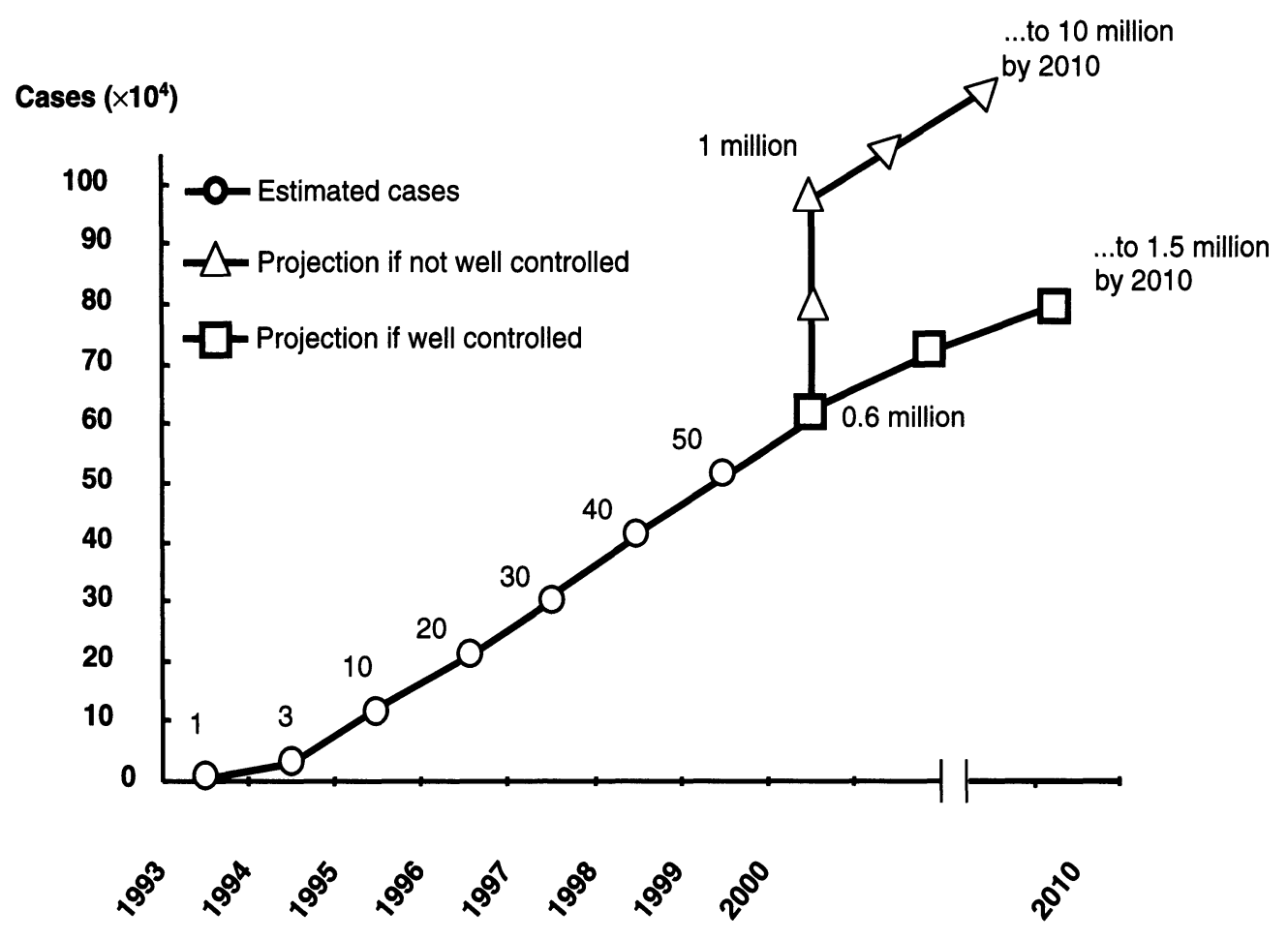

FIGURE 6. Estimated HIV/AIDS Cases, 1993-2000, and Predicted Cases, 2010

in October 1989 with the identification of HIV infection in 146 drug users in southwest Yunan (these were imported cases of HIV), and was followed by an epidemic in a few counties in Dehong prefecture. During this phase some HIV infections were also reported among IDU in other parts of China. At the same time, a small number of HIV infections were reported among laborers returning from abroad, STI patients, and FSW; the number of cases increased gradually during this time.

\section{The Third Phase}

The third phase began in 1995 when HIV transmission among IDU spread beyond one prefecture in Yunan province and into various regions such as Xinjiang, Guangxi, and Sichuan. Simultaneously, a large number of HIV infections were reported among blood/plasma donors in central China, mainly rural blood donors who moved frequently and were more likely to transmit HIV to different regions. Furthermore, cases of HIV infection among STI patients and FSW also increased.

\section{Characteristics of the HIV Epidemic in China}

\section{The Epidemic is Increasing Dramatically}

Currently, there is a low prevalence of HIV nationally but a high prevalence in specific populations and certain regions. The main transmission routes are through intravenous drug use and, in the past, through the sale of blood and plasma. In 2003, according to a China CDC survey supported by WHO, UNAIDS, and US CDC, China has 840,000 people living with HIV/AIDS, among which 80,000 are AIDS cases. Although the adult prevalence rate is less than $0.1 \%$, the epidemic has spread to 31 provinces and the number of reported HIV/AIDS cases has increased significantly. 
Increasing Number of AIDS Cases and AIDS-Related Deaths

According to the annual case reports on HIV/AIDS, there has been a significant increase in the cumulative number of HIV/AIDS cases reported. Since 2001, China has approached a peak of AIDS cases and AIDS related deaths. In the 15 years from 1985 to 2000, the cumulative number of AIDS cases reported was 880 , with 496 deaths, while the number of AIDS cases and related deaths between 2001 and 2002 were 1742 and 716 respectively. The reported number of AIDS cases in 2002 increased by $44 \%$ compared with 2001. In some villages in counties of Henan and Anhui provinces where the HIV epidemic is acute, concentrations of AIDS cases and deaths have occurred since 2001.

\section{The HIV/AIDS Epidemic Is Spreading from High-risk Populations to the General Population}

Although sharing injection equipment among IDU is the main transmission route, the proportion of sexually transmitted HIV infections also increased from 5.5\% in 1997 to $10.9 \%$ at the end of 2002. Data from sentinel surveillance indicated that the HIV prevalence among FSW is increasing, and Mother to Child Transmission (MTCT) has continued to increase since the first reported case in 1995.

\section{Risk Factors Exist for a Generalized HIV Epidemic}

High risk behaviors among IDU has increased, including sharing needles and syringes. There still is a low rate of condom use in China. There is a persistent lack of HIV/AIDS related knowledge among Chinese, coupled with severe social discrimination against PLWHA. A high reproductive tract infection (RTI) prevalence rate among rural women is increasing the risk of HIV transmission in some areas. There remains a risk of HIV infection through blood transfusions and iatrogenic infections. Significantly, there is an imbalance in economic development, which has produced poverty in different areas and increased the risk of HIV infections. If China is not able to address these risk factors, the HIV/AIDS epidemic will not be controlled and there will be both serious individual and socio-economic repercussions. The AIDS epidemic will become a serious problem threatening national security and prosperity, social stability, and economic development.

\section{High Risk Factors}

\section{Migrant Population}

The current internal movement of temporary and permanent migration across China is without precedent. Estimates suggest that the total number of migrants, both temporary and permanent, may be as high as 120 million; that is, some $15 \%$ of the total labor force. This number, while extremely large, is actually increasing. A number of additional factors make the migrant labor force particularly vulnerable to HIV infection.

The mere fact that they are mobile makes it extremely difficult to reach this population. Migrants easily escape efforts at education and health promotion. AIDS knowledge within the migrant population is, therefore, very low.

Second, migrants in China are often young and live for extended periods of time away from the social pressure of their families and communities. They are frequently unmarried or are living apart from their spouses and children. Nevertheless, they are still sexually active and often have casual sex, often with FSW, without protection.

\section{Sexually Transmitted Infections (STI)}

STIs have risen sharply from 23,534 reported cases in 1985 to a level of 859,040 reported cases in 2000 (see Figure 7). Again, experts estimate that the actual number of STI cases in the country is 6-8 million. In most 


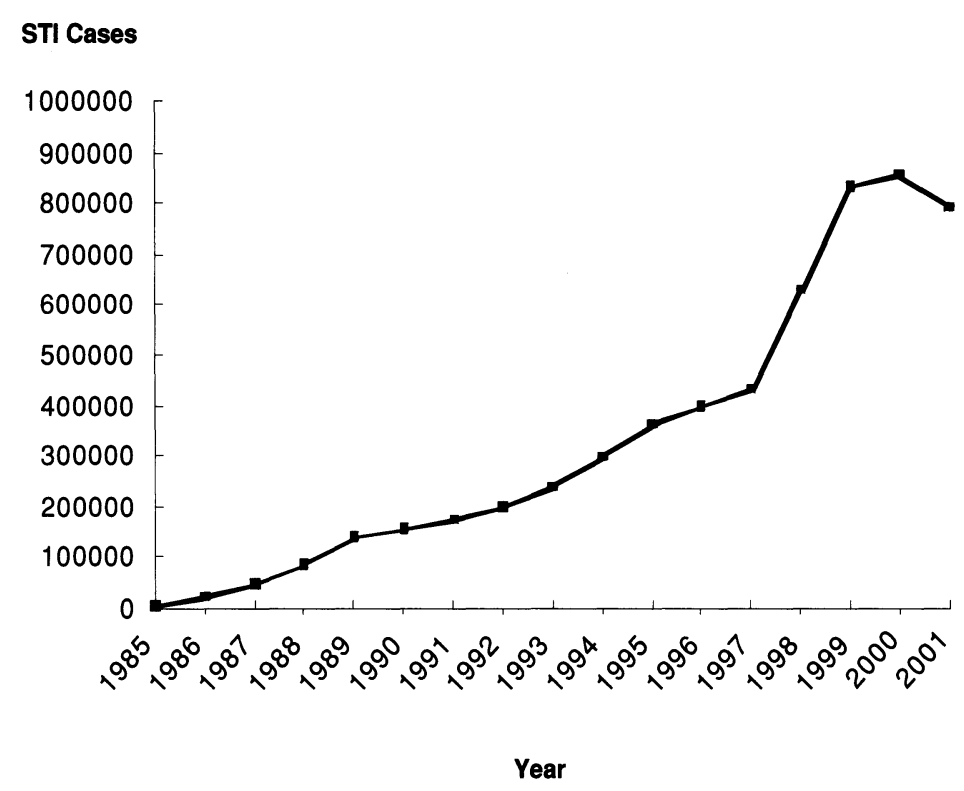

FIGURE 7. STI Cases in China by Year, 1985-2001

urban areas, the majority of STI patients come from within the nonresident population.

\section{Drug Use}

The most recent and severe increase in both drug trafficking and drug use in cities throughout China is closely connected with the migrant and nonresident population. There are some one million known drug users recorded by public security in Mainland China. The actual number is estimated to be between 3-5 million (Jianhua et al., 2003).

\section{Commercial Sex Work}

Underground sex work is becoming a very serious issue. FSW working in most cities are often not permanent residents, but are migrants from distant regions. The number of FSW and clients arrested in 1985 was just 25,000 , but in 1998 this number increased to 398,000 (see Figure 8 ). One estimate of the actual number of FSW in China is about six million (Jianhua et al., 2003). Sexual transmission of HIV is expected to gradually increase and will likely become the major route of HIV transmission among the general population.

\section{Men Who Have Sex with Men (MSM)}

In China, homosexual activities are not illegal, but they are not acceptable in most of society. Most homosexual people are still under social pressure to hide their sexual orientation and to be married. Very few studies on homosexuality have been carried out in China. It is estimated that the total number of MSM in China is over 18 million. Because of high-risk behaviors and relatively little protection in this population, rates of HIV and STI infection among MSM are higher than in the general population. Based on one survey, the HIV infection rate in this population increased from $2.5 \%$ in 1998 to $5.5 \%$ in 2001 (Zeng, 2003).

\section{Hazards Related to Blood and Blood Products}

There are two main sources of donated blood in China: unpaid donations (either requested or voluntary donations), and paid donations. A small number of Chinese donate blood without being paid, but in general, people in China are reluctant to donate blood because of deep-rooted cultural beliefs. At 


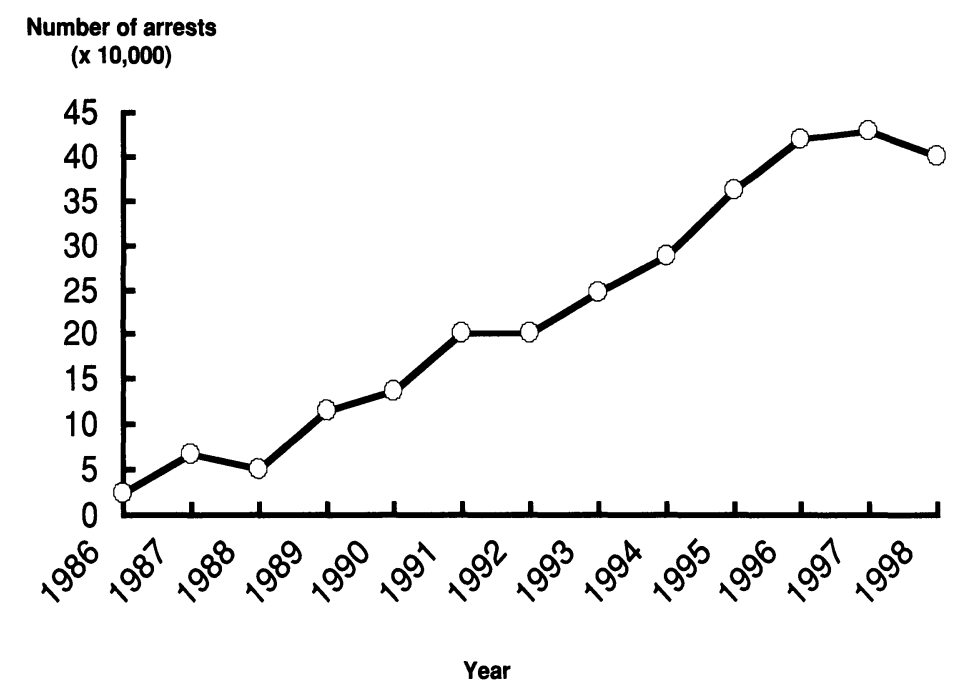

FIGURE 8. Female Sex Workers (FSW) and Their Clients Arrested in China (1986-1998)

present, there are about three million paid blood donors in China, many of them selling plasma during the 1990s. Most of these paid donors live in the poor provinces of central and southern China such as Henan, Hebei, Anhui, Shanxi and Guizhou. Some of them are migrants or are unemployed and rely on plasma sales for their primary income.

\section{Inadequate Infection Control in Health Care Settings}

In some rural and remote areas, hygiene is poor, and due to a lack of equipment and, in some cases, inadequate training, the sterilization of medical instruments is difficult. In addition, even in big cities disposable needles and syringes are often not destroyed, leaving the possibility that they will make their way into the larger community and be reused.

\section{Challenges}

With a population of 1.3 billion in China, the effective control of HIV/AIDS is not only a benefit to China but also to the world. The Chinese government has issued The Chinese Mid-long Term Plan for HIV/AIDS Prevention and Control (1998-2010) and
The Five-Year Action Plan for HIV/AIDS Prevention and Control (2001-2005). Many provinces and ministries have carried out strategic planning and a great deal of practical work has been done. Now a comprehensive preventive and control system has been developed. The whole society has been mobilized and many sectors from central to local levels all have become involved in the related activities. In cooperation with the Chinese government, NGOs in China (especially the Chinese Foundation for Prevention of STD and AIDS, and the Chinese Association for STD and AIDS Prevention and Treatment) have played a very important role in HIV/AIDS prevention and control. Many effective efforts have been made, such as health education, communitybased care, social mobilization, and high-risk population interventions. However, there are a lot of challenges and difficulties related to HIV/AIDS prevention and control in China. Support and assistance from various arenas both within China and abroad are seriously needed.

\section{Countermeasures}

It is critical to take strong action against this epidemic now, otherwise, this window 
of opportunity to control the HIV/AIDS epidemic in China will be lost. HIV/AIDS education interventions are the most important strategy for controlling the HIVAIDS epidemic. If countries fail to adopt education and intervention programs, about 46 million people, mostly in Sub-Saharan Africa, China, and India, would become infected (Zeng, 2003; Altman, 2002). A wider application of education and intervention programs would prevent 29 million people from becoming infected worldwide (Altman, 2002). This means that $70 \%$ of HIV infections in countries with rapidly growing epidemics (like China) would be prevented (Zeng, 2003). Thailand is a good example, where 5-6 million HIV infections have been prevented (Zeng, 2003). The cost of an aggressive prevention program would be USD\$ 1000 for each infection prevented, much less than the cost of treating people once they have become infected (Zeng, 2003).

According to our experiences in the Shandong Weifang City, the cost of an HIV/AIDS education and intervention program would be RMB 2 yuans for each person in China, especially in counties and rural areas. Thus, the cost for carrying out an education and intervention program throughout China would be RMB 2.6 billion yuans for 3-5 years. Such a program may prevent 6 million people from becoming infected with HIV by 2010. Conquering HIV/AIDS requires a combination of prevention and treatment programs, yet aggressive efforts to prevent the spread of HIV/AIDS are far less expensive than treating those infected in an epidemic.

Recently, the Chinese government proclaimed that it would strengthen its efforts to fulfill the responsibility of containing and controlling the HIV/AIDS epidemic. The Chinese government has recognized HIV/AIDS prevention and treatment to be important tasks. The government will further define its goals in combating the disease, identify governmental responsibilities, and improve evaluation, supervision, and monitoring of activities.
Accountability for the success or failure of prevention programs will be maintained and enforced.

Second, China is committed to providing free treatment and medicines to PLWHA who have economic difficulties. This health program will cover low-income PLWHA in urban areas, and all patients in rural areas. Moreover, central and local governments will invest more than 10 billion yuan to strengthen the medical assistance system for infectious diseases, and train professionals in comprehensive HIV/AIDS prevention and treatment modalities.

Thirdly, the Chinese government will improve its laws and regulations, and intensify interventions against dangerous behaviors that contribute to the spread of HIV/AIDS. Public awareness campaigns will be launched to educate the public and encourage citizens to participate in HIV/AIDS prevention and treatment efforts. Laws against illegal acts like drug trafficking, drug use, commercial sex work, and illegal blood collecting and distribution will be enforced, while drug-free communities and healthy sexual behaviors will be promoted.

The Chinese government will also work to protect the legitimate rights of PLWHA and oppose social discrimination. Throughout the 124 counties where the Chinese "care" project will be established, integrated measures including antiretroviral treatment, health care, and social programs will be adopted. The government will provide economic aid to PLWHA living in poverty, and their children will be able to attend school tuitionfree.

Finally, the government will be more active in international cooperation relating to HIV/AIDS. The HIV/AIDS situation in China has caused both concern and commitment from the international community. China welcomes the continued financial and technical support from the governments of other nations and international organizations. Meanwhile, the Chinese government is ready to be active in the global fight against 
HIV/AIDS and fulfill its responsibilities and obligations. The Chinese government has pledged USD $\$ 10$ million to the Global Fund to Fight AIDS, Tuberculosis and Malaria. This money will support the HIV/AIDS prevention and treatment efforts of developing countries, fulfill the development goals of the UN Millennium Declaration, and contribute to the control of HIV/AIDS prevalence and the realization of global HIV/AIDS control objectives.

\section{SARS EPIDEMIC AND CONTROL}

\section{SARS Epidemic in China and Worldwide}

Severe acute respiratory syndrome (SARS) originated in November 2002 in the Guangdong Province of China and has subsequently spread to more than 30 countries and regions, including Hong Kong, Taiwan, Vietnam, Canada, and Singapore, infecting approximately 8459 patients and resulting in more than 800 deaths. In China alone, 5327 cases and 349 SARS-related deaths have been reported.

SARS is an emerging infectious disease, and an effective treatment remains unavailable. The underlying causes that led to the SARS epidemic in China are complicated, yet two critical factors are China's large transitory population and the unpreparedness of some Chinese agencies to recognize and fight the epidemic.

Although the transmission mechanism of the agent or agents causing SARS has yet to be fully understood, it is believed that SARS is transmitted probably mainly by droplet secretions, fomites, or close person-to-person contact. The incubation period of SARS ranges from one day to 12 days, with a median of four days. The SARS epidemic in China was characterized with both hospital clustering and family clustering. The disease affected people in all age groups, with patients aged between 2 months and 92 years. Nevertheless, $71 \%$ of patients were between 20 and
49 years old. The male-to-female ratio was $1: 1.6$. There was no statistically significant difference between men and women in the mortality rate; however, the mortality rate was associated with age and co-morbidities. According to WHO, the fatality rates are as follows: $<1 \%$ for below age $24,6 \%$ for ages $25-44 ; 15 \%$ for ages $45-64 ;>50 \%$ for above age 65 (Zheng, 2003).

\section{SARS Epidemic Control in China}

The outbreak and rapid spread of SARS in China caused fear and concern in ordinary citizens and caught the immediate attention of both the Chinese government and the world. The responses taken were as follows:

1. To protect people's health, the Chinese government set up a national command center to coordinate the efforts of disease treatment, control, and prevention. Thus, disease control became a national priority.

2. A massive nationwide campaign to educate people to take precautions was launched and decisive measures were mandated by all levels of the government to control the epidemic throughout China.

3. Both medical experts and the media played extremely important roles in disseminating scientific knowledge to the public, and raising awareness of SARS prevention.

4. Soon after the national command center was set up, effective strategies based on the experience in fighting against SARS epidemic in Guangdong Province were formulated and adopted.

5. Four effective principles against the outbreak were summarized and adopted: early identification and diagnosis, early reporting, early isolation, and early treatment. To prevent further cases, patients were treated locally and controls against nosocomial infection were instituted. Thus, in a surprisingly short period of time, SARS was controlled and daily normal life was restored.

6. During the SARS epidemic, public health professionals played an extremely important role in education and prevention. Epidemiologists worked very closely with physicians treating patients, helped identify local sources of the epidemic, and conducted outbreak investigations. These epidemiologists visited patients' families 
and co-workers, and identified both suspected cases and super-spreaders. Numbers of identified cases were reported to the government daily, and the government then informed the public about the status of the outbreak. Under the leadership of the national command center, public health professionals helped government agencies strengthen the safety of public places by improving ventilation and reducing unnecessary activities. These professionals also educated people about how to minimize their risk of being infected, and how to enhance their immune system to fight SARS. Based on the information collected from hospitals and communities, public health professionals determined that both definite and suspected cases of SARS should be isolated for 12 to 14 days.

7. To control the epidemic, the Chinese government instituted scientific research on SARS etiology, treatment, and prevention, and encouraged international collaborations in these areas. On March 12, 2003, the WHO issued a global warning about the epidemic, and took unprecedented measures to effectively prevent the disease from spreading to unaffected countries and regions. The WHO dispatched a team of experts to China and set up a global disease control network in 10 countries including China. Chinese health professionals made important contributions toward identifying a novel coronavirus as the causal agent of SARS.

\section{SARS and the Public Health System}

The SARS epidemic has simultaneously evolved as both a significant challenge to humans' health, as well as a social and public health management problem. As an emergency crisis, the SARS epidemic has had at least the following 4 characteristics:

1. Unpredictability: SARS infections were unpredictable and, at least initially, the mode of transmission was in question.

2. Exigency: Swift attention to the infections, and quick treatment of cases was necessary to prevent further infections.

3. Social consequences: The SARS epidemic caused an imbalance in the social order, and damaged economic development, through rampant fear and anxiety. For a time, it was the most important issue facing China and overshadowed other priorities.

4. Worldwide implications: The SARS epidemic has spread from China and affected the entire world.

The SARS epidemic has created a significant challenge for the Chinese public health system. The Chinese government has responded by establishing and strengthening a prevention system to ensure an effective response to any future epidemic. Scientific studies on the origin of SARS, its pathogenesis and immunology, potential anti-SARS drugs and vaccines, and animal models are being conducted.

\section{REFERENCES}

Altman, L.A. (2002). Modest Anti-AIDS Efforts Offer Huge Payoff, Studies Say, New York Times. July 5, 2002.

China HIV/AIDS Information Network. (2002). Situation of HIV/AIDS Epidemic and Its Prevention and treatment in China in 2002. Beijing, China.

Chinese Association of Preventive Medicine. (1993). Review and Prospects for Chinese Health Antiepidemic System.

Chinese Association of Preventive Medicine. (2003). Review and Prospects for Chinese Health Antiepidemic System.

Jianhua, Y., Qi, X., Tao, J., and Houbao, X. (2003). Simulation of Impact of Policy and Law Environment on HV/AIDS Spreading in China. United Nations Development Program.

Ministry of Public Health. (1990). A Brief Introduction on China's Medical and Health Services. Beijing, China.

Ministry of Public Health. (2002). National Situation of Morbidity and Mortality of Infectious Diseases in China. Beijing, China.

Zeng, Yi. (2003). Health Education and Intervention Are Major Strategies for AIDS Control. Chinese Journal of Health Education. 11(19): 846848.

Zheng, L. (2003). SARS and Response to Emergency Public Health Events. Sciences Publishing House, Beijing. 